\title{
Femoral nerve conduction in diabetes and chronic occlusive vascular disease
}

\author{
J. S. CHOPRA ${ }^{1}$ AND L. J. HURWITZ \\ From the Department of Neurology and the Metabolic Unit, Royal Victoria Hospital, Belfast, \\ Northern Ireland
}

Gassel (1963) devised a method for direct measurement of femoral nerve conduction and found this useful in differentiating neuritis of the femoral nerve from other causes of proximal neurogenic and muscular diseases. He discussed the relevant anatomy of the terminal motor fibres in the skeletal muscles, with particular reference to the quadriceps femoris muscle. He also described the theoretical considerations of measurement of the latency time and the initial response of the muscle action potential in relation to its distance from the end plate zone, and the significance of the positioning of the recording electrodes. In the present study a similar technique to Gassel's was used to measure the conduction time in the femoral nerve in patients with diabetes mellitus and in non-diabetic patients suffering from peripheral vascular disease. Such a study of femoral nerve conduction would also help to establish the site of nervous system involvement in patients with mainly motor signs and tendon reflex changes.

\section{MATERIAL AND METHODS}

Femoral nerve conduction studies were performed in 45 diabetics without neuropathy and 32 with objective evidence of clinical neuropathy. The peripheral blood vessels in all these patients were normally palpable. Thirty-three patients with peripheral vascular disease who were considered non-diabetic on the basis of a normal oral glucose tolerance test were examined. Fifty-one subjects without muscle disease and without

'Supported by the Medical Research Council. peripheral vascular disease and who had normal levels o blood sugar constituted the control group. Thirty-seven of these had a normal oral glucose tolerance test and 14 had a blood sugar level below $110 \mathrm{mg} \% 2$ hours aftek food. The age range in all four groups was between $20-$ and 69 years and each group had comparable numbers distributed per decade. Table I outlines the main symptoms and signs found in the patients. Eight patientso with diabetic neuropathy gave a history of severe pain iñ the muscles of the thighs; the knee jerks were absent in seven of these and diminished in the other. Of these eightw patients, atrophy of the quadriceps muscles was present in three and another showed wasting of leg muscles belofw the knees and visible fasciculations in the quadrices,$\infty$ these four closely resembled 'diabetic amyotrophy' described by Garland (1955) (Table II). All the patientswith diabetic neuropathy had mild to severe sensory signs. In nine out of 32 cases the neuropathy was $\frac{\mathbb{O}}{O}$ acute onset, while in the rest the onset was insidiogss. Three of these nine cases were known diabetics and undere treatment, while in six the diabetes was discovered affer they presented with neurological complaints. Extensols plantar reflexes were not elicited in any patient.

In the peripheral vascular disease gro $\mathrm{vp}$, two patients suffered from Raynaud's phenomenon, one had a con-o genital abnormality of the arteries, and another patients had a block at the bifurcation of an atheromatous aorta due to embolism as a result of rheumatic heart disease

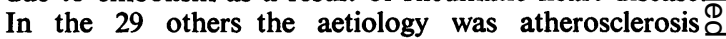
Peripheral pulsations below the femorals were not pal $\vec{\Rightarrow}$ pable on one or both sides in all the patients, except in two with Raynaud's phenomena in whom only the posterior tibial and dorsalis pedis pulsations were absent. Femoral pulsations were absent in seven andgrossly diminished in another 10 . The presenting symp

TABLE I

SYMPTOMS AND SIGNS IN PATIENIS

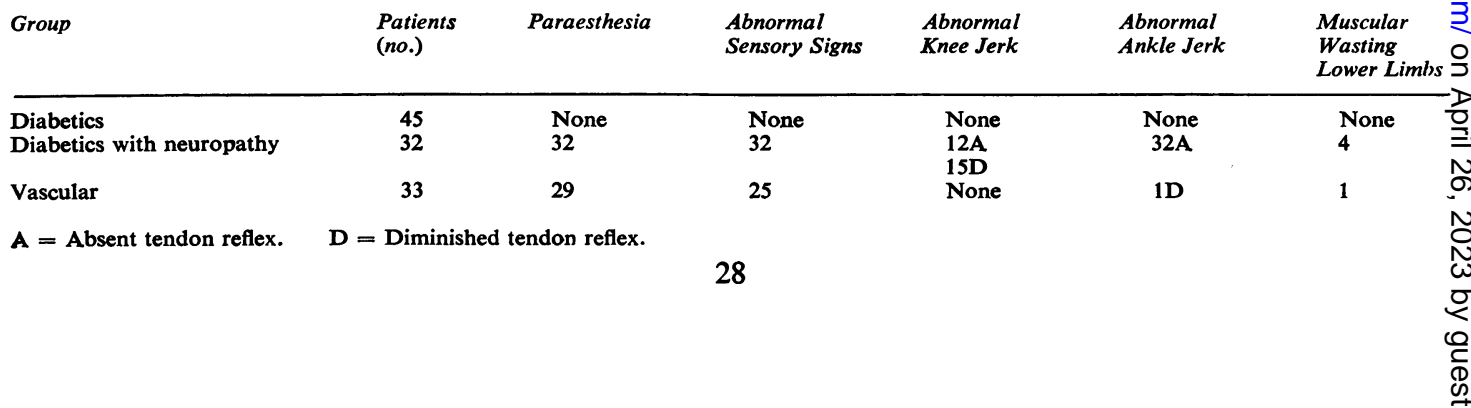


TABLE II

FOUR PATIENTS WITH FEATURES RESEMBLING DIABETIC AMYOTROPHY

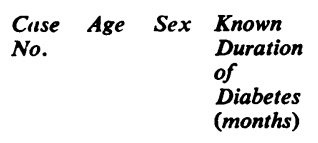

1

$53 \quad M \quad 6$

2

$67 \quad$ F 4

3

69 F 8

4

$69 \quad$ F 9

Symptoms

\begin{abstract}
Abnormal Neurological Signs
\end{abstract}
Femoral Nerve

Lat. Pop. Nerve

\begin{tabular}{llll}
\hline Latency (msec) & $\begin{array}{l}\text { Conduction } \\
\text { Velocity } \\
m / \mathrm{sec}^{1}\end{array}$ & $\begin{array}{l}\text { Motor } \\
\text { Conduction } \\
\text { Velocity } \\
\mathrm{m} / \mathrm{sec}^{2}\end{array}$ \\
\hline Proximal Distal & & $\begin{array}{l}\text { Lat } \\
\text { m }\end{array}$
\end{tabular}

Pain in both thighs 1 Wasting legs $R>L$. Fascicula-

$\begin{array}{ll}\text { yr with loss of weight, tions } \mathbf{R} \text { thigh and dorsum foot. } \\ \text { discovered diabetic } 6 & \text { Little loss of power. Absent }\end{array}$

mth ago and treated

with oral anti-diabetic

drugs. Symptoms

became worse with

weakness of $R$ leg

Severe pain $R$ thigh $4 \frac{1}{2}$

mth. Weakness $R$ leg 4

mth. Initial treatment

with oral anti-diabetic

drugs. Pain and weak-

ness $L$ leg 2 mth

vibration below iliac crest and

hyperalgesia feet. Tendon

reflexes absent lower limbs

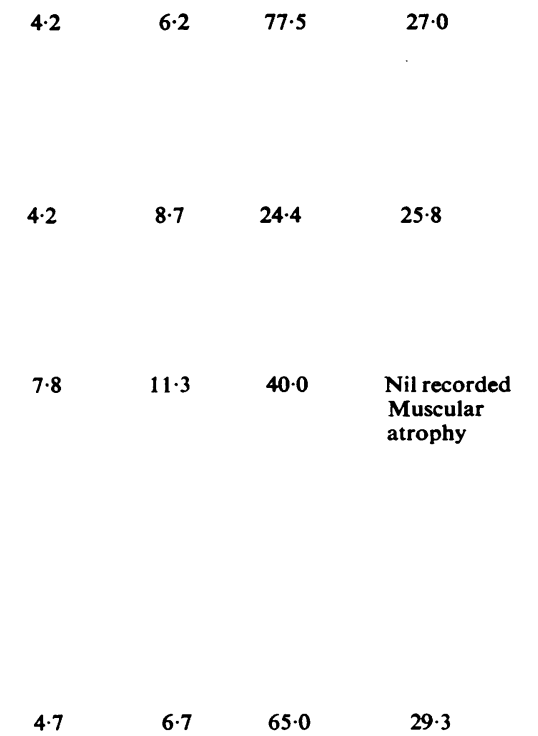

$6 \cdot 2$

$77 \cdot 5$

$27 \cdot 0$

Wasting both legs. $R$ thigh $1 \frac{1}{2}$ in

thinner than L. Bilateral foot

drop. Absent cottonwool and

diminished pin prick

over feet. Absent vibra- .

tion ankles. Tendon reflexes

absent in lower limbs

Onset with severe pain

$\mathbf{R}$ thigh 9 mth. Weakness legs $7 \mathrm{mth}$. Loss of power $R$ leg $2 \mathrm{mth}$. Treated with oral therapy

Marked wasting both legs in

entire length $\mathbf{R}>\mathbf{L}$. No move-

ment whole of $\mathbf{R}$ leg. Severe

weakness left hip flexion and

moderate weakness $L$ hip

extension, $L$ knee flexion and

extension and $L$ plantar and

dorsal flexion. Impaired cotton-

wool and pin prick $\mathbf{R}$ leg, and

joint position ankles. Absent

vibration below iliac crests.

Tendon reflexes absent both

knees and $R$ ankle. $L$ ankle

diminished

Severe pain $L$ thigh 1 Wasting both legs. $R$ thigh 1 in.

less in circumference than $L$.

yr ago and later found to be diabetic. Treated with oral hypo-

glycaemic agents. Pain $\mathrm{R}$ thigh $7 \mathrm{mth}$, paraesthesia feet $3 \mathrm{mth}$ and extension, knee flexion and extension. Bilateral weakness of dorsal flexion ankles with foot drop and plantar flexors. Absent

\begin{tabular}{|c|c|c|c|}
\hline $4 \cdot 2$ & $8 \cdot 7$ & $24 \cdot 4$ & 25.8 \\
\hline 7.8 & $11 \cdot 3$ & $40 \cdot 0$ & $\begin{array}{l}\text { Nil recorded } \\
\text { Muscular } \\
\text { atrophy }\end{array}$ \\
\hline $4 \cdot 7$ & $6 \cdot 7$ & 65.0 & $29 \cdot 3$ \\
\hline
\end{tabular}

\begin{tabular}{|c|c|c|c|}
\hline $4 \cdot 2$ & $8 \cdot 7$ & $24 \cdot 4$ & 25.8 \\
\hline $7 \cdot 8$ & $11 \cdot 3$ & $40 \cdot 0$ & $\begin{array}{l}\text { Nil recorded } \\
\text { Muscular } \\
\text { atrophy }\end{array}$ \\
\hline $4 \cdot 7$ & $6 \cdot 7$ & 65.0 & $29 \cdot 3$ \\
\hline
\end{tabular}
cottonwool up to ankles and impaired to knees. Absent vibration ankles. Absent tendon reflexes both ankles and $\mathbf{R}$ knee

$\mathbf{R}=$ right.

$\mathbf{L}=$ left.

${ }^{1}$ Range in controls $=56 \cdot 2-94 \cdot 1 \mathrm{~m} / \mathrm{sec}($ mean $=74 \cdot 1)$ tom in 31 patients was intermittent claudication and in two was Raynaud's phenomenon. Twenty-nine patients complained of paraesthesia though in some only to leading questions. In 25 patients $(75 \cdot 7 \%)$ there were abnormal neurological signs with absent or diminished light touch sensation and impaired pin prick and vibration in varying degrees below the knees. The ankle jerks were diminished only in one elderly patient, and there was slight weakness and wasting of the quadriceps in one patient and partial foot drop with weakness of peroneal muscles in another.

The femoral nerve was stimulated just below the inguinal ligament where it is located lateral to the femoral artery (Fig. 1). The skin was prepared by shaving the area, gentle abrasion, and cleaning with ether. A bipolar surface electrode having an electrode diameter of $10 \mathrm{~mm}$ and centre-to-centre separation of $30 \mathrm{~mm}$ was used for stimulating the nerve trunk, placed vertically over the nerve. A thin lead plate ground $3 \times 8 \mathrm{~cm}$ was placed between the stimulating and the recording electrodes The muscle action potentials were recorded by means of two concentric needle electrodes (DISA 13.K.51), with a needle diameter of $0.45 \mathrm{~mm}$ and length of $30 \mathrm{~mm}$. The distal needle electrode was inserted into the rectus femoris muscle $9-10 \mathrm{~cm}$ above the upper border of the patella to avoid entering the suprapatellar bursa. The proximal needle electrode was placed about $10-15 \mathrm{~cm}$ from the stimulating electrode, the former in a straight line with the stimulating and distal recording electrodes.

The stimulus was a rectangular pulse of $0.7 \mathrm{msec}$ duration and derived from the DISA multistim with a double shielded output transformer and frequency of $1 / \mathrm{sec}$. The output impedance of the transformer was $15 \mathrm{~K} \Omega$. The maximal primary voltage of the stimulator was $50 \mathrm{~V}$ and a transformer output with a ratio of 1:1.5. Figure 1 is a diagrammatic representation of the method and shows a normal recording. The recordings from the two electrodes were amplified and displayed on the two 
TABLE III

MEAN LATENCIES FROM STIMULATING POINT TO PROXIMAL AND DISTAL RECORDING POINTS

Group

Mean Latency (msec)

Mean Distance (cm)

Proximal

Proximal

Distal

$12 \cdot 7 \pm 0 \cdot 2$

$27 \cdot 8 \pm 0 \cdot 1$

$4 \cdot 2 \pm 0 \cdot 1$

$6 \cdot 0 \pm 0 \cdot 1$

$13.0 \pm 0.2$

$27 \cdot 7 \pm 0 \cdot 4$

$\mathrm{n}=32(54 \cdot 0)$

Ischaemics

$\mathrm{n}=33(52 \cdot 1)$

Controls

$3 \cdot 7 \pm 0 \cdot 1$

$12.5 \pm 0.2$

$27.6 \pm 0 \cdot 4$

$3 \cdot 7 \pm 0 \cdot 1$

$5.8 \pm 0.1$

$12 \cdot 7 \pm 0 \cdot 2$

$28 \cdot 2 \pm 0 \cdot 3$

$\mathrm{n}=51$ (44.5)

Figures in brackets = mean age.

$\mathbf{n}=$ number of cases.

Figures after \pm standard error.

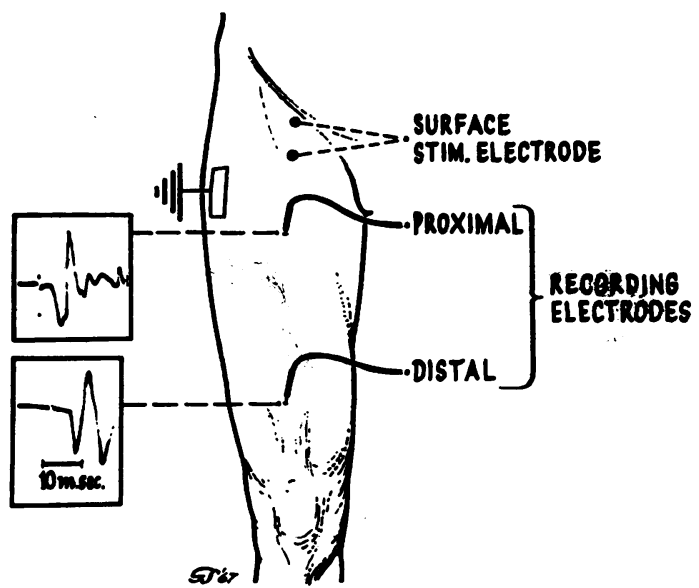

FIG. 1. Arrangement of stimulating and recording electrodes; muscle action potentials are from a control subject.

independent cathode ray tubes of the electromyogram (DISA), with a time base of $1 \mathrm{msec} / \mathrm{mm}$. The stimulus was supramaximal and amplification adjusted so that the muscle potentials could be visualized on the cathode ray screens. Three photographic recordings were made of the maximal motor response and then the polarity of the stimulus was reversed and the same number of recordings made again. The film was developed and latencies to the proximal and distal recording electrodes measured from the stimulus artefact to the initial deflection of the muscle potential. Mean latencies were calculated from the measurements obtained with the bipolar stimulating electrodes at each polarity. The distance from the midpoint between the two stimulating electrodes and each recording electrode was measured with a tape. The conduction velocity in the segment of the nerve between the proximal and distal recording electrodes was calculated in metres per second by substracting the proximal latency from the distal latency and dividing the distance between the two recording electrodes by the conduction time. $x(7 \cdot 8)$

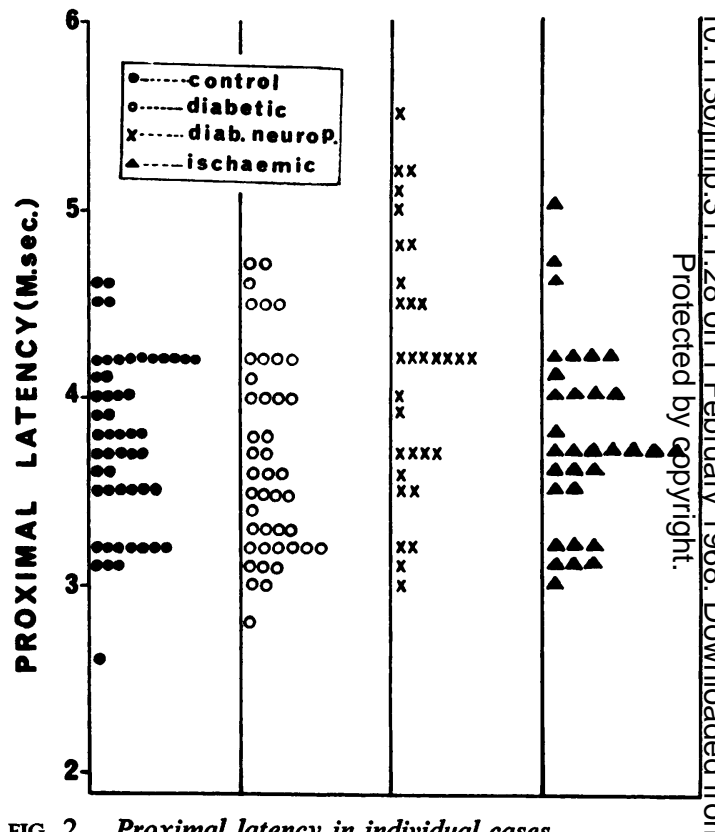

FIG. 2. Proximal latency in individual cases.

\section{RESULTS}

The mean latencies from the stimulating point to the proximal and distal recording points are given in Table III, and Figs. 2 and 3 illustrate the latencies. plotted graphically from individual cases. The analysis of variance showed that the differences in the latencies between the groups were highly sig-을 nificant $(P<0.001$; Table IV). The mean latencies to $>$ the proximal and distal points were elevated in the diabetics with and without neuropathy, significantly so in the latter, in comparison with the vascular group and the controls (Table V(a)). No significant 

$x(11 \cdot 3)$

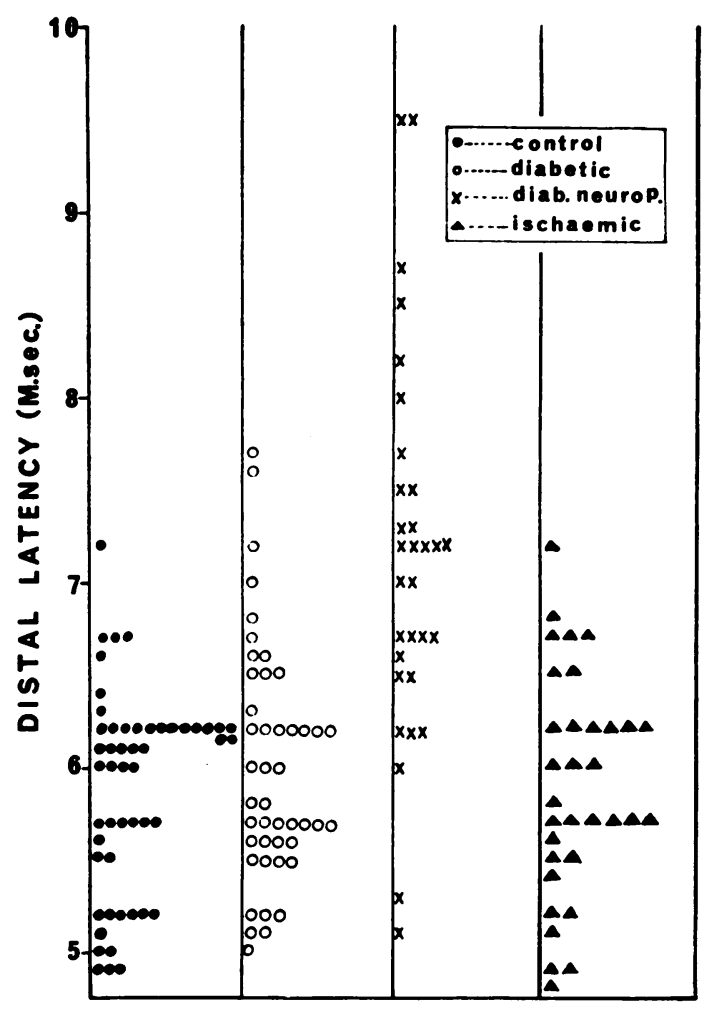

FIG. 3. Distal latency in individual cases.

TAB LE IV

ANALYSIS OF VARIANCE

\begin{tabular}{|c|c|c|c|c|}
\hline \multicolumn{2}{|c|}{ Mean Latency (msec) } & \multicolumn{2}{|c|}{ Mean Distance $(\mathrm{cm})$} & \multirow{2}{*}{$\begin{array}{l}\text { Mean } \\
\text { Conduction } \\
\text { Velocity } \\
(\mathrm{m} / \mathrm{sec})\end{array}$} \\
\hline Proximal & Distal & Proximal & Distal & \\
\hline $\begin{array}{c}6.94 \\
<0.001\end{array}$ & $\begin{array}{l}26.11 \\
<0.001\end{array}$ & $\begin{aligned} & 0.56 \\
< & 0.6\end{aligned}$ & $\begin{array}{r}0.57 \\
<0.6\end{array}$ & $\begin{array}{r}25.16 \\
<0.001\end{array}$ \\
\hline
\end{tabular}

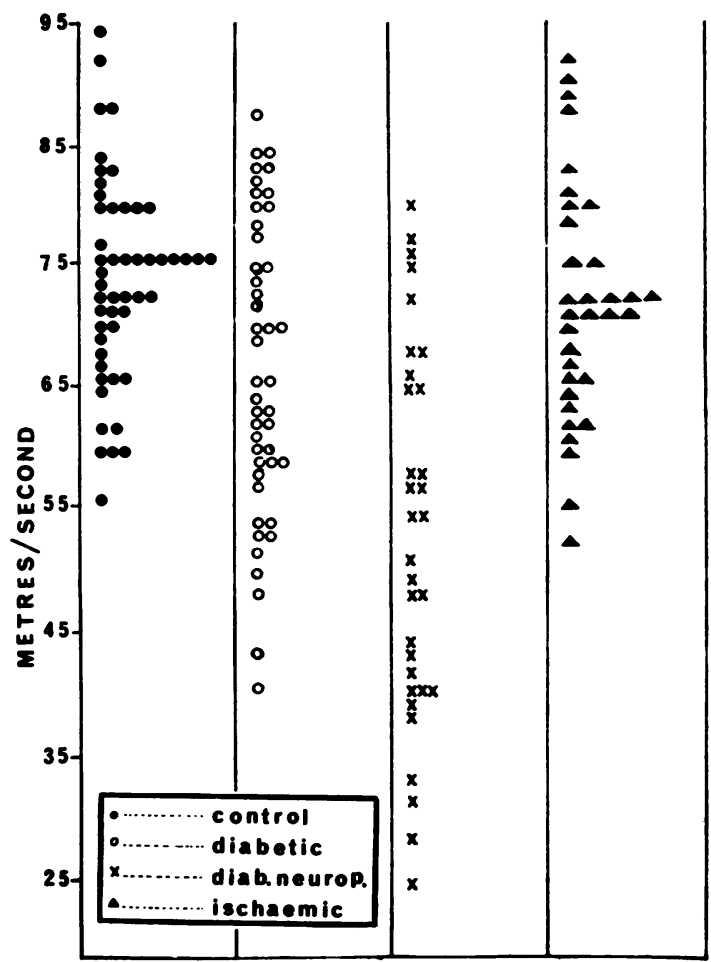

FIG. 4. Motor nerve conduction velocity between proximal and distal recording points in individual cases.

difference between the controls and vascular group was noted.

CONDUCTION VELOCITY Table III shows the mean conduction velocity between the proximal and distal recording points and in Fig. 4 the conduction velocities are plotted from individual cases. The variation of conduction velocities among the four groups was highly significant $(P<0.001$; Table IV).

TABLE V

DIFFERENCES OF MEAN BETWEEN GROUPS

\begin{tabular}{|c|c|c|c|c|c|}
\hline$I-I V$ & $I I-I V$ & $I I I-I V$ & $\begin{array}{c}\text { (a) Latency } \\
\text { Proximal Recording Point } \\
\text { II-I }\end{array}$ & $I-I I I$ & $I I-I I I$ \\
\hline $0 \pm 0 \cdot 1$ & $0.5^{*} \pm 0.1$ & $0 \pm 0 \cdot 1$ & $0.5^{*} \pm 0.1$ & $0 \pm 0.1$ & $0.5 * \pm 0.1$ \\
\hline $0 \cdot 2 \pm 0 \cdot 1$ & $1 \cdot 4^{*} \pm 0 \cdot 2$ & $\begin{array}{c}0 \pm 0.2 \\
\text { (b) Conduction Velocity }\end{array}$ & $\begin{array}{r}1 \cdot 2 * \pm 0 \cdot 2 \\
\text { ty between Proximal and Dis }\end{array}$ & $\begin{array}{c}0.2 \pm 0.2 \\
\text { al Recording Points }\end{array}$ & \\
\hline$I V-I$ & $I V-I I$ & $I V-I I I$ & $I I-I$ & $I I I-I$ & $I I I-I I$ \\
\hline $7 \cdot 2 * \pm 2 \cdot 3$ & $21 \cdot 1^{*} \pm 2 \cdot 5$ & $2 \cdot 0 \pm 2 \cdot 5$ & $13.9 * \pm 2 \cdot 6$ & $5 \cdot 2 \pm 2 \cdot 6$ & $19 \cdot 1^{*} \pm 2 \cdot 8$ \\
\hline
\end{tabular}

*P significant at 0.05. Figure after $\pm=$ standard error. I $=$ Diabetics. II $=$ Diabetics with neuropathy. III $=$ Vascular. IV $=$ Controls. 
The mean conduction velocities in diabetics with and without neuropathy are significantly slow in comparison with the controls. Mean conduction velocity is also significantly slow in diabetics with neuropathy in comparison with the vascular group and with diabetics without neuropathy. There was no significant difference between controls and the vascular group (Table V(b)).

The range of conduction velocity in diabetics without neuropathy was $40.5-87.5 \mathrm{~m} / \mathrm{sec}$; in diabetics with neuropathy $24.4-80 \mathrm{~m} / \mathrm{sec}$; in the vascular group $50-92.2 \mathrm{~m} / \mathrm{sec}$, and in controls $56 \cdot 2-94 \cdot 1 \mathrm{~m} / \mathrm{sec}$. In eight diabetics without and 18 diabetics with neuropathy and in one case from the vascular group the conduction velocities were slower than $56.2 \mathrm{~m} / \mathrm{sec}$, the lower limit recorded in the controls.

Table III shows the mean distances in the four groups from the stimulating to the recording points. Variation in the distances to the proximal and distal recording points among the groups was not significant $(P<0.6$; Table IV) and so could not have influenced the prolonged latencies in the diabetics.

\section{DISCUSSION}

Bruns (1890) first drew attention in diabetics to symptoms of severe pain in the thighs followed by wasting of the leg muscles. This syndrome became more fully appreciated much later when, in 1953, Garland and Taverner described severe pain followed by weakness and wasting in muscles of the thighs and legs in five diabetics (three had extensor plantar responses) and termed it 'diabetic myelopathy' suggesting changes in the spinal cord. In a later publication (1955) Garland re-named the syndrome 'diabetic amyotrophy'.

Hirson, Feinmann, and Wade (1953) also observed weakness and wasting of the quadriceps femoris muscle in 12 diabetics with neuropathy and commented on this being a most striking feature. Goodman (1954) presented 17 cases with femoral neuropathy, 16 of whom had diabetes mellitus, and suggested that the incidence of involvement of the femoral nerve in diabetes was higher than is generally realized. With control of the diabetes the condition reversed. Skanse and Gydell (1956) described bilateral femoral nerve lesions in a diabetic patient in whom electromyography revealed a neurogenic lesion but it was difficult to differentiate between a central or peripheral nerve lesion. At necropsy they discovered degenerative changes in the myelin sheaths, but no degeneration of anterior or posterior roots. Involvement of the femoral nerve in many other maladies has been described such as in haemophilia (Aggeler and Lucia, 1944; Lyons, 1953), in osteoarthritis of the hip joint (Moffie,
1953), and in abdominal surgery by pressure from retractors (Johnson and Montgomery, 1958). Noned of the patients in the present series had such damage Fourteen of the 19 cases of femoral neuropathye described by Calverley and Mulder (1960) has diabetes mellitus. They postulated that at least in some of these diabetics, neuropathy developed as a result of acute alteration in the blood supply to the femoral nerve. Symptoms were acute in eight of their cases but of insidious onset in six. Electro-: myography of the quadriceps femoris muscle wass: not helpful in differentiating between a central and peripheral lesion. Gassel (1963) observed prolonged latency of response to femoral nerve stimulation in nine patients out of 23 , and there was good correla $\stackrel{\nabla}{\square}$ tion between the absence of the knee jerk and the prolongation of the latency. He did not find pros longed latency or slow conduction velocity in any of the cases with motor neurone disease or primarymuscular disorder, and concluded that elevation in latency of response to femoral nerve stimulation is found only in peripheral neuritis of the femorap nerve.

The present study reveals that there is a significant elevation in latency in diabetics with neuropat and reduction in the conduction velocity in diabetife with and without neuropathy. None of the diabefines without neuropathy had symptoms referable to the femoral nerve and yet conduction was relative delayed. In eight cases it was below the lower lingie recorded in controls. The present study is in agrege ment with nerve conduction studies carried out $\$ y$ other workers that motor nerve conduction velocitites are reduced in diabetics with and without neuropathy (Lawrence and Locke, 1961; Mulder, Lamberto Bastron, and Sprague, 1961; Skillman, Johnson Hamwi, and Driskill, 1961). This would indicate tha 5 the affection of the nerves in diabetes mellitus is of कै generalized metabolic nature, as it is very unlikely tha $\mathbb{R}$ the femoral nerve has been involved on a vascula basis in all patients with and without neuropathy having abnormal conduction studies. It is cons ceivable that ischaemia of the femoral nerve was noț severe enough among the cases in the vascular group as many had palpable femoral pulses, but in some with the block at a level higher than the femoraf artery the conduction velocities and latencies were normal. Twelve patients with diabetic neuropathy had absent knee jerks. In another 15 they were diminished, which would indicate a correlation between the change in the knee reflex and elevation in the femoral latency. Four patients with diabetio neuropathy who had muscular wasting and sensory. signs, but no extensor plantar response, would resemble the clinical picture of Garland's amy otrophy; in two of them the femoral conduction 
velocities were slow and latencies elevated, while in three motor conduction velocities in the lateral popliteal nerve were slower than the lower limit recorded in controls. These findings are in agreement with the conclusions of Gilliatt and Willison (1962). These authors found motor nerve conduction slowed in the lateral popliteal and median nerves in two patients who had mixed motor and sensory neuropathy and many features resembling 'diabetic amyotrophy'. In one of their patients the latency of the knee jerk was increased. They suggested from these observations that the amyotrophy of Garland was essentially a motor neuropathy with a particular tendency to affect proximal muscles. The spinal cord may also be involved in some cases as Garland (1955) found an extensor plantar response in some of his cases, but none of the patients in the present study had extensor plantar responses. The present study reveals that femoral nerve conduction is a useful diagnostic test and easy to perform and will differentiate a neuropathy of metabolic aetiology from one related to ischaemia. The lateral popliteal, the median, and ulnar nerves are at present those commonly sampled for clinical studies. However, these nerves are by their anatomical sites particularly liable to entrapment and external trauma. Although a metabolic process whether acquired or hereditary will predispose these nerves to the effect of trauma, trauma by itself could cause over the years significant neural damage in 'non-predisposed nerves'. The femoral nerve is less liable to entrapment and trauma and therefore one might expect conduction studies in this nerve to be a more true reflection of the state of the peripheral nerve.

\section{SUMMARY}

A study of femoral nerve conduction in 77 diabetics (32 with neuropathy), 33 non-diabetic patients suffering from peripheral vascular disease, and 51 controls is described. Both the proximal and distal latencies are prolonged significantly in diabetics with neuropathy, in comparison with diabetics without neuropathy, vascular group, and controls. The motor conduction velocity is significantly slow in diabetics with and without neuropathy. It is suggested that diabetic amyotrophy is a peripheral neuropathy, especially involving motor nerves, and the aetiological cause for diabetic neuropathy is mainly metabolic.

We are grateful to Dr. D. A. D. Montgomery and Mr. H. C. Dales for permission to study their patients and for their help. Professor G. M. Bull and Professor J. Vallance-Owen kindly allowed us facilities in the Department of Medicine, Queen's University of Belfast. The work has been supported by a grant from the Medical Research Council.

\section{REFERENCES}

Aggeler, P. M., and Lucia, S. P. (1944). The neurologic complications of hemophilia. J. nerv. ment. Dis., 99, 475-500.

Bruns L. (1890). Uber neuritische hähmungen beim diabetes mellitus. Berl. klin. Wschr. 27, 509-515. Quoted by Skanse, B., and Gydell, K. (1956), Acta med. scand., 155, 463-468.

Calverley, J. R., and Mulder, D, W. (1960). Femoral neuropathy. Neurology (Minneap.), 10, 963-967.

Garland, H. (1955). Diabetic amyotrophy. Brit. med. J., 2, 1287-1290.

- and Taverner, D. (1953). Diabetic myelopathy. Ibid., $1,1405-1408$.

Gassel, M. M. (1963). A study of femoral nerve conduction time. Arch. Neurol. (Chic.), 9, 607-614.

Gilliatt, R. W., and Willison, R. G. (1962). Peripheral nerve conduction in diabetic neuropathy. J. Neurol. Neurosurg. Psychiat., 25, 11-18.

Goodman, J. I. (1954). Femoral neuropathy in relation to diabetes mellitus; report of 17 cases. Diabetes, 3, 266-273.

Hirson, C., Feinmann, E. L., and Wade, H. J. (1953). Diabetic neuropathy. Brit. med. J., 1, 1408-1412.

Johnson, D. A., and Montgomery, R. R. (1958). Femoral neuropathy in abdominopelvic surgery. Med. Ann. D.C., 27, 513-514, 562.

Lawrence, D. G., and Locke, S. (1961). Motor nerve conduction velocity in diabetes. Arch. Neurol. (Chic.)., 5, 483-489.

Lyons, J. B. (1953). Femoral nerve lesion in haemophilia. J. Irish med. Ass., 32, 110-111.

Moffie, D. (1953). Neuritis of the femoral nerve. Folia psychiat. neerl., 56, 813-820. Quoted by Calverley, J. R., and Mulder, D. W. (1960). Femoral neuropathy. Neurology (Minneap.), 10, 963-967.

Mulder, D. W., Lambert, E. H., Bastron, J. A., and Sprague, R. G. (1961). The neuropathies associated with diabetes mellitus: a clinical and electromyographic study of 103 unselected diabetic patients. Neurology (Minneap.), 11, 275-284.

Skanse, B., and Gydell, K. (1956). A rare type of femoral-sciatic neuropathy in diabetes mellitus. Acta med. scand., 155, 463-468.

Skillman, T. G., Johnson, E. W., Hamwi, G. J., and Driskill, H. J. (1961). Motor nerve conduction velocity in diabetes mellitus. Diabetes, 10, 46-51. 